\title{
The Students' Use of Google Classroom in Learning English
}

Department of English Education,Tanjungpura University, Pontianak

e-mail: urai.salam@untan.ac.id

\begin{abstract}
This study investigates the students' use of Google Classroom in English language learning. The data were derived from Likert Scale questionnaires including open-ended questions distributed to 119 English Education students. There were five aspects covered in the questionnaire: access to Google Classroom, perceived usefulness, communication and interaction, instructional delivery and students' satisfaction. Meanwhile, open-ended inquired students' real experiences. The result showed the mean score with the following distribution: 4,49 for easy access to GC, 3,93 for perceived usefulness, 3,63 for communication and interaction, 4,10 for instructional delivery, and 3,82 for students' satisfaction. Some students shared their experiences in using Google Classroom. Some of them said that Google Classroom brought their courses to their face so that they can participate and continue work on their classes beyond the working hours. Even many of them still worked and uploaded their assignments till midnight. In spite of these positive findings, the study revealed that some students fell into serious addiction to social media technology.
\end{abstract}

Keywords: Students' experience; Google Classroom; English Language Learning

\section{Introduction}

The advancement of technology like what we experience today, majority, if not all, occur in the developed world. Many studies reported summaries of the benefits of digital technologies to support students' learning activities (Martono and Salam, 2017). Digital technology creates rich learning environments to allow students not only to access information and communication they need, but also to provide venues so that they could exercise inquiry learning, critical thinking, creativity, and collaboration (Akcan, 2018; Bond, 2020; Lin et al., 2020). Meanwhile, in the developing countries, with wide gaps among them, educational institutions still struggle to embrace technology with full acceptance. Among the reasons are there infrastructures, teachers' acceptance, and students' skills to use for their learning purposes (Ifinedo, Rikala, \& Hämäläinen, 2020; Lucas, 2020).

The students the instructors teach are in their Net generation. It goes without saying that they are very familiar with the use of networked technology that allows them to access information and communication technologies such as Instagram, WhatsApp, Facebook, Line and so forth, not exceptionally games and entertainment applications. Enriched with and being familiar to such kind of technology, the students should have extended their learning experiences (Gan, Menkhoff, \& Smith, 2015). However, such privileges do not guarantee learning to happen. Educators are urged to compete for their students' attention as they are skillful in multitasking among those who are multi-living (Conrad \& Dunek, 2020). Crittenden, Biel, and Lovely (2019) argue that the students who use technological devices during teaching learning processes in the classroom tend to lack their attention to their teacher explanation compared to those who take notes using hand writing. They are distracted by what appear in their devises. This phenomenon, in fact, indicates the students' inability to use ICT for learning intention.

The students' ability to use and to accept such technologies for learning activities requires instructional design provided by their teachers. In developing countries, some higher educational institutions are still in their ways to introduce policies to oblige their educators to integrate technologies in their instructional delivery. In such situation, both lecturers and students entail transformation of their perception of technology in their educational practices.

\footnotetext{
${ }^{*}$ Corresponding author.

Received 20 July 2020; Accepted 21 September 2020; Available online 01 December 2020 (C) 2020 JPI. All Rights Reserved
} 
On the one hand, the lecturers demand upgrading skills in technology use, particularly for those who are in the group of digital immigrant (Alaniz \& Wilson, 2015). Digital immigrants, according to Alaniz and Wilson, are lecturers who are not comfortable employing technology in their instruction. These lecturers need convincing debate to encourage them utilizing technology. This is in line with what (Rushby and Surry's, 2016) suggestion that investing in technology does not guarantee technology acceptance. They continue to argue that particularly in developing countries where technology is not equally installed, there has been little change in traditional educational practices despite great investment in technological infrastructures. That is why it is important to have initiative to help digital immigrants possess sufficient confidence to integrate technology into their teaching practices.

In a similar vein, the students, mostly digital natives, if not all, are greatly familiar with the current technology. They, as described by (Mudrikah et al., 2019; Turkle, 2005), are equipped with wearable technological devices. For them technologies are not simply tools but constitute an environment that emerges new culture; for young generation living on the screen is inseparable from living in the real world (Turkle, 2011). Situated in technology rich environments, the students are so much attached to digital devices. The young generation as always on; they are busy with social networking, video entertainments, and gaming online. The challenge is whether the students are skillful in employing technology for learning endeavors.

Their reluctance to use technology for learning purposes could be caused by the insufficiency and the scarcity of the introduction of technology to drive learning, and hence they are not accustomed to using technology in their learning processes. When they are encouraged by their universities to use technology in the learning process, the students need to adapt to that specific use of technology. In other words, it is not because they are not familiar with the technology, but more because they are unfamiliar with utilizing technology for learning purposes.

Google Classroom nowadays has become one of the popular teaching platform used by teachers and lectures. Google Classroom had managed to host over 30 million assignments uploaded by teachers and students. It indicates that this application is an interesting medium for teaching-learning process that can be brought to our Education (Iftakhar, 2016).

Google Classroom is a web-based course management system (CMS). It provides venue for instructional delivery and learning processes where students obtain education through communication, interaction, and discussion. This is also a platform for teacher to deliver their courses; they can assign students to upload works and other assignments. By this way, Google Classroom facilitates teachers and lecturers in creating and organizing assignments, feedback, and communication with the classes (Shaharanee, Jamil, \& Rodzi, 2016b). They believe that Google Classroom is a good innovation in teaching because using this application, the educators and the students can obtain many benefits including easy access wherever and whenever they want as long as they have the internet connection. By this way, the students feel belonging to their courses as it blends with their social engagement (Coffman \& Klinger, 2016).

A study found that Google Classroom is an appropriate application for LMS because it is already linked to university's and school's system and it seemingly meets the students' request for a simpler interface allowing more interaction (Heggart \& Yoo, 2018). The students just need to have the class code from the teachers or lecturers. Then, after having the code, they can open the Google Classroom by clicking "Join Class", and writing the code given and the last is by clicking "enter" or "ok". Afterward, the students will be successfully enrolled to the class. In addition, the educators and the students can also interact actively in the application. Google Classroom has features that enable both educators and students communicate in group or privately for every task posted by the educators.

Furthermore, Google Classroom can create a new environment of learning for the students (Shaharanee et al., 2016a). The students and the educator will not see each other directly, hence, it can trigger the students to ask more about the lesson learned in the application. They can also discuss the answers of any questions from their friends. The educator will control the questions and answers from the students. It means that when the students have gone out of the track, the educator could re-direct the students to the right one 
again. It goes without saying that by implementing Google Classroom in English teaching, learners will have more space and time to work on asynchronous pace basis.

The study shown that the nature of asynchronous technology has enabled students' interaction and collaboration (O'Rourke \& Stickler, 2017). By this, they obtain socio-affective advantages, including sharing opinions, insights, feeling, and works, establishing network, helping and motivating each other, and providing scaffolding each other. The significant conclusion from this study is that asynchronous technology democratizes the classroom process where every student could participate including less participative, unconfident, and shy students. For foreign language students, the study by (Satar \& Akcan, 2018; Hew \& Cheung, 2008) suggested that the implementation of on-line discussions improved their English language development and also increased more engagement compared to that in face-to-face class situations. In other words, the use of asynchronous technology could be a better choice for learning English as it does not only allow students to reach more speaking English people around the world, it also provides scaffolding for those who had linguistic insufficiency (Osborne, Byrne, Massey, \& Johnston, 2018).

In terms of learning English as foreign language, using asynchronous communication platform like Google Classroom suggests less pressure so that it encourages more participation, more collaboration, more confidence (Satar \& Akcan, 2018). Those studies found that students participations increased exponentially in asynchronous environments. The absence of physical attendance reduces their anxiety that usually hindrance their participation. In such situation, applying course management system in the process of teaching is one of the real alternatives. Google classroom can be the solution to this issue. The current study investigated the students' use of Google Classroom and their experiences in how the application has helped them maintain their learning English.

\section{Method}

This study employed a descriptive design. In this design, the investigator does not interfere in a situation where the data come from as it could damage the natural process of the phenomena being captured (Cohen et al., 2007). This way, the design tries "describes and interprets what is" (Best \& Kahn, 2006). They explain that this design can be used to explore the students' opinions about a phenomenon, the existing processes, and the current trends that develop among populations. The current study investigated the students' use of Google Classroom (GC) in their learning English activities as well as their experiences in how it became part of their learning endeavors.

The participants of this study were 119 college students from English major. They had used Google Classroom largely for almost every subject they pursued for last two semesters. The activities in GC varied from subject to subject. In addition, some lecturers used GC in different level of activities from simple posting of announcements, uploading materials and assignments, to full blended learning; they used Google Classroom extensively in their course delivery.

The data of this study were derived from two sources: Likert Scale questionnaires with five scale (Table 1) and open-ended questionnaires. The former were in five parts with 29 items. They were developed to reveal the students' access to Google Classroom and perceived usefulness of it (Davis, 1989). The questionnaires also included perception on quality communication and interaction, instructional delivery, as well as students' satisfaction (Shaharanee et al., 2016a). Meanwhile, the latter were to discover the students' meaningful experiences during their study. Using open-ended questionnaire, the students were required to write short description about how Google Classroom had helped them maintain their learning English as well as its challenges. All questionnaires were validated by lecturers who employed Google Classroom to some degree from the English Education Department. 
Table 1. Likert Scale.

\begin{tabular}{ccccc}
\hline $\mathbf{1}$ & $\mathbf{2}$ & $\mathbf{3}$ & $\mathbf{4}$ & $\mathbf{5}$ \\
\hline Strongly disagree & Disagree & Neutral & Agree & Strongly agree \\
\hline
\end{tabular}

The data were analyze to determine the mean score of each item. Then, to identify the verbal interpretation of the range of mean score, the writer used Bringula's interval (Table 2) of 5-point scale (Bringula, 2012). The open-ended questionnaires were analyzed using thematic analysis (Creswell, 2012).

Table 2. Verbal Interpretation.

\begin{tabular}{cll}
\hline Rate & Verbal Interpretation & Range \\
\hline 4 & Strongly Agree & $4.51-5.00$ \\
4 & Agree & $3.51-4.50$ \\
3 & Neutral & $2.51-3.50$ \\
2 & Disagree & $1.51-2.50$ \\
1 & Strongly Disagree & $1.00-1.50$ \\
\hline
\end{tabular}

\section{Results}

The findings are presented in two parts following the research questions. The first one reports the students' use of Google Classroom Application in learning English. Meanwhile, the second part elucidates the students' experiences in using Google Classroom.

The Students' Use of Google Classroom

Table 3 reports the students' easy access to Google Classroom. The data indicated that almost all students responded strongly agree toward easy access of GC. There are five aspects in the questionnaire with the average score of 4,49. Two aspects received the highest score, Easy to sign in $(4,80)$ and Easy to send and receive assignment $(4,60)$. Meanwhile the lowest score fell in Easy to understand the system (4.20). This indicates that some students might still feel unfamiliar with Google Classroom. This could be the first experience for them. The complete scores can be seen from the Table 3.

Table 3. The students' access to Google Classroom

\begin{tabular}{lcl}
\hline \multicolumn{1}{c}{ Statements } & Mean & Verbal Interpretation \\
\hline Easy to sign in & 4,80 & Strongly Agree \\
Easy to access course materials & 4,46 & Agree \\
Easy to send and receive assignment & 4,60 & Strongly Agree \\
Easy to submit the assignment & 4,46 & Agree \\
Easy to operate & 4,46 & Agree \\
Easy to understand the system & 4,20 & Agree \\
Mean & 4,49 & Agree \\
\hline
\end{tabular}

Eventually, the data reveal above average between agree and strongly agree. This can be inferred that Google Classroom application for learning English was easily accessed by the students including accessing course materials, submitting assignments, and receiving tasks from lecturers.

The next table, Table 4, exhibits the perceived usefulness of Google Classroom. This means that the scores indicate the students' perception if GC facilitates their learning English. The questions cover the usefulness of Google Classroom in terms of the quality of learning, interaction, submitting assignments, engaging activities, receiving feedbacks, grading system, and consistency in course structures. The mean score for all those aspects was 3,93 verbally interpreted as agree. 
Table 4. Mean Scores of Perceived Usefulness of Google Classroom

\begin{tabular}{lrl}
\hline Statements & Mean & $\begin{array}{l}\text { Verbal } \\
\text { Interpretation }\end{array}$ \\
\hline Excellent learning activity & 3,83 & Agree \\
Excellent medium for social interaction & 3,56 & Agree \\
Punctual assignment submission & 4,53 & Agree \\
Productive course activities & 3,83 & Agree \\
Useful feedback by the lecturer & 4,13 & Agree \\
Useful grading system for monitoring progress & 3,76 & Agree \\
Providing clear subject description & 3,90 & Agree \\
Mean & 3,93 & Agree \\
\hline
\end{tabular}

As can be seen in Table 4 above, the highest mean goes to Punctual assignment submission (4.53). This is true as Google Classroom has notification for almost due assignments. Meanwhile, the lowest mean goes to Excellent medium for social interaction $(3,56)$. This implies that the students preferred to use other social media for quick communication channel like WhatsApp, Instagram, and Facebook. In other words, they did not use GC for communication. In spite of these conditions, the overall results indicated that the students agreed that Google Classroom brought benefits for their study.

The next section, Table 5, shows the results of communication and interaction. In fact, the table was the detail exploration of the second question of Table 4, i.e., Excellent medium for social interaction. Therefore, the average mean score of Table 5 was similar to that of second question of Table 4.

Table 5. Mean Scores of Communication and Interaction Through GC

\begin{tabular}{lcl}
\hline Statements & Mean & $\begin{array}{l}\text { Verbal } \\
\text { Interpretation }\end{array}$ \\
\hline Comfortable communication channel & 3,86 & Agree \\
Engaging students and productive discussion. & 3,70 & Agree \\
Co-sharing in discussion forum & 3,63 & Agree \\
Enthusiastic lecturers in teaching & 3,33 & Neutral \\
Friendly and approachable lecturers & 3,60 & Agree \\
Comfortable interaction among participants & 3,67 & Agree \\
Mean & 3,63 & Agree \\
\hline
\end{tabular}

Even though the average mean score was 3,63 , verbally interpreted as agree, all scores in Table 5 are below 4 or below agree in Likert scale. This means that Google Classroom was perceived as less preferable for communication medium, approximately as indicated by question two of Table 4. Meanwhile, referring to the Table 5, the highest mean goes to Comfortable communication channe/ with 3,86 mean score and the lowest one belongs to Enthusiastic lecturers in teaching with 3,33 mean score.

The following section displays the mean score of students' opinions for Instruction Delivery. The data indicate the level of students' opinions about how Google Classroom had been used by their lecturers to deliver their instruction. Instruction Delivery includes clear instruction, deadline, course topic update, participation rules, and giving feedback.

Table 6. Mean Scores of Instruction Delivery in GC

\begin{tabular}{lcl}
\hline Statements & Mean & $\begin{array}{l}\text { Verbal } \\
\text { Interpretation }\end{array}$ \\
\hline Clear instructions for course learning activities. & 3,93 & Agree \\
Showing due dates or duration for some activities. & 4,36 & Agree
\end{tabular}




\begin{tabular}{lrl}
\hline Statements & Mean & $\begin{array}{l}\text { Verbal } \\
\text { Interpretation }\end{array}$ \\
\hline Clear course topics. & 4,00 & Agree \\
Keeping the participants on course tasks & 4,06 & Agree \\
Feedback for better understanding of the course. & 3,80 & Agree \\
Mean & 4,10 & Agree \\
\hline
\end{tabular}

The data shows that all aspects in Instructional Delivery received scores which are verbally interpreted as agree. It indicates that the students claimed that their lecturers used Google Classroom for their instructional delivery and did necessary activities. For example, the students responded that Showing due dates or duration for some activities $(4,36)$; Keeping the participants on course tasks $(4,06)$; Clear course topics $(4,00)$; and Clear instructions for course learning activities $(3,93)$. All these evidenced the use of GC for instructional delivery.

The last part of the questionnaires results reveals the students' satisfaction with the use of Google Classroom in learning English. As presented in Table 7, the students' satisfaction mean score was 3,82 interpreted as agree. In other words, the students were satisfied in using Google Classroom for their learning English.

Table 7. Mean Scores of Students' Satisfaction with GC

\begin{tabular}{lrl}
\hline Statements & Mean & $\begin{array}{l}\text { Verbal } \\
\text { Interpretation }\end{array}$ \\
\hline Meeting the students' personal goals. & 3,76 & Agree \\
Preferable platform to every subject & 4,16 & Agree \\
The first choice in active learning LMS & 3,53 & Agree \\
Motivating learning platform & 3,86 & Agree \\
Mean & 3,82 & Agree \\
\hline
\end{tabular}

\section{The Students' Experiences in using Google Classroom for Learning English}

Even though not all participants in this study responded to open-ended questionnaire, some did share experiences using Google Classroom intensified their activities contributing to their learning. This section presents three main findings from qualitative data.

In the first place, the participants claimed that Google Classroom has eliminated the border of the classroom. The sense of anytime and anyplace really happens when their lecturers used GC for some courses. The students' claims as can be seen in Figure 1, suggest that their lives glue together between their social life in social media and their learning activities taking place in GC.

$$
\begin{aligned}
& \text { Sosmed is not only daily activities but it becomes my hourly activities. I } \\
& \text { mean no hour passes without checking my mobile phone like checking } \\
& \text { IG [Instagram], WA [WhatsApp], and Facebook, but now plus GC } \\
& \text { [Google Classroom]. } \\
& \text { We have GC chat, IG chat, WA chat, and FB chat. We spent lots of time } \\
& \text { busy chatting about everything, but GC only for our school. } \\
& \text { Now I can't separate between my school and my social life; I do them } \\
& \text { all at once. }
\end{aligned}
$$

Figure 1. Excerpt 1

With Google Classroom as part of the classroom process, there was no clear-cut definition of classroom. The students continued working even though official class hour had 
ended and class room had closed. The students continued interacting as normal official classroom processes, not as extension hours when they worked on their usual homework. The interesting part is that they were so attached to their mobile phones that no moment without checking them where they engaged in their Google Classrooms as well as their social congregation.

In the second place, as can be seen in Figure 2, integrating Google Classroom in the classroom processes intensified the students' awareness of their study. In fact, with technology they felt that they were forced to focus on their schoolwork.

Google Classroom brought my class to my face. Very often I feel overwhelmed as I received notification from my GC to check almost due assignments or to do that, to do this.

Flexible hours mean never ending working, anytime any place.

Flexible time means I can customized my learning hours and working hours. I usually post my assignment midnight.

Figure 2. Excerpt 2

These quotes indicate that the students became more attached to their classroom. The nature of flexibility even required them to increase their commitment to always go back to their school related activities in the middle of their engagement in social media routines.

Unlike the first two findings, the third point (Figure 3. Excerpt 3) indicates that the students were upset with inventing new life and new habits. They were overwhelmed with chained attractive information and entertainments through their gadgets and found themselves wasting time on unproductive activities. They were actually aware that they procrastinated things they should have done; in most cases, they did not know what and why exactly they were doing.

I think my phone is my life. I spend hours and hours with my gadget. As long as I remember, I have changed my sleeping hours since I owned my own phone. Night is my day. I just could not stop clicking, listening, watching, reading till I forgot the time, forgot to do things.

I don't know what I am doing, but still I can't give up.

I don't know if I am learning or not but for sure I always stick to my phone.

Figure 3. Excerpt 3

These quotes imply that the students grew their addiction to gadgets so they kept being distracted from their study.

\section{Discussion}

The utilization of various course management systems or 'platforms' in university is growing as the blended and online learning gain their popularity. Various studies are reported on how instructors used different platforms including Moodle (Eskandari \& Soleimani, 2016; Khabbaz \& Najjar, 2015), Edmodo (Balasubramanian, Jaykumar, \& Fukey, 2014; Purnawarman, Susilawati, \& Sundayana, 2016), Google Classroom (Kumar \& Bervell, 2019), WebCT (Salam, 2009), and any other online or cloud-based tools. The reasons for their popularity are that they promote intensive engagement in learning activities evidenced with 
greater interaction among students-students-instructors. suggest that The use of course management system could alter instructional delivery in tertiary education (Kumar \& Bervell, 2019); Tao, et al., 2018; Yulian \& Salam, 2014; Borup et al., 2020).

All these are in line with the current study's results. Easy access and perceived usefulness of Google Classroom (GC) suggested that the students' daily routine interacting in their social media glued together with academic activities facilitated by GC. By this, the students boosted their commitment to their study and enhanced their learning. For example, while using WhatsApp, Instagram, Facebook and other social media accounts to interact with their networks, the results indicate that the students simultaneously participated in GC. They claimed that Google Classroom had brought their course in front of their face to mean the close proximity between social and academic intercourse. This reinforces (Sulissusiawan \& Salam, 2017) study, that claimed that flexible time and environments advanced students' commitment to their learning.

Furthermore, (Mercer \& Dörnyei, 2020) argue that learning commitment is critical for successful learning in the fast-paced reality of the twenty-first century; their commitment save them from irrelevant activities and unproductive exploration intensified by social media. The introduction of technology does not seem to manifest in task pursuit automatically, because although a student with technology savvy is not likely to always do well at various distractions. They need to struggle to get familiar with school related activities and academic tasks among multiple channels of temptation. There are simply too many competing activities on a student's mind in the middle of technology-rich environments. We must ensure that the students' positive commitment win at the end.

In addition, the current study showed that Google Classroom provided extended opportunities for students to congregate with peers as well as to continue their school-work. The data from questionnaire suggested that GC had helped them submit their assignments on time $(4,53)$. They also claimed that flexibility means not only to allow them to customize their study hours, but also to increase their commitment to work till midnight. The students' ability to maintain their engagement to work so hard indicates students' positive disposition without being ruined by the abundance of other pressing and ever-salient distractions.

The students of (Satar \& Akcan, 2018) held that Google Classroom values a constructive result on their learning endeavours as well as social participation with their networks and therefore result in positive attitudes for this kind of technology. Furthermore, the study by (Amadin et al., 2018) found that Google Classroom enabled students to achieve better schoolwork and increases learning productivity.

Despite those benefits to have access to information and communication technology, some students still failed to gain the merit of technology. It sounds pity to find students distracted and even worsted by technology. Technology is genuinely created to help humankind but for those who fail to self-regulate themselves will be disadvantaged. This study exemplifies students being trapped by technology due to their inability to prioritize their study and their life. They failed to understand the use of technology for learning. They indeed need help to get back to their Google Classroom and stop procrastination.

Numerous studies in fact show similar findings. Students with mix experiences and feelings both being motivated and optimistic with access to rich perspectives of information, but at the same time being overloaded with distraction (Sulissusiawan \& Salam, 2017). The other study, (Conard \& Marsh, 2014) found that students, even though they were interrupted by simultaneous information access, managed to accomplish their work. Conard and Marsh argued that their students used some advantageous multitasking strategies. In a similar vein, (Judd, 2015) investigated the tract records of computer logs during students' independent learning sessions. The study found that the students switched tasks frequently in averagely every 31 second across Academic, Communication, Information, Recreation and Applications tasks. However, students managed to keep almost half of the activities related to their studies.

\section{Conclusion}

The current study has provided significant findings about how course management system, Google Classroom (GC), was experienced by students in learning activities in their 
English courses. It reported such aspects of GC as access, usefulness, communication, instructional delivery, and overall students' satisfaction as well as their engagement using GC for their learning. The study suggested that the students had no problem to access any facilities provided by Google Classroom. Hence, they obtained benefits to helped them submit their assignments on-time, obtain feedback from their lecturers, and course descriptions and communication with their instructors. Overall, the students satisfied using Google Classroom in their courses.

\section{References}

Alaniz, K., \& Wilson, D. (2015). Naturalizing digital immigrants: The power of collegial coaching for technology integration: Rowman \& Littlefield.

Amadin, F., Obienu, A., \& Osaseri, R. (2018). Main barriers and possible enablers of Google apps for education adoption among university staff members. Nigerian Journal of Technology, 37(2), 432-439. doi:10.4314/njt.v37i2.18

Balasubramanian, K., Jaykumar, V., \& Fukey, L. N. (2014). A Study on "Student Preference towards the Use of Edmodo as a Learning Platform to Create Responsible Learning Environment". Procedia - Social and Behavioral Sciences, 144, 416-422. doi:10.1016/j.sbspro.2014.07.311

Best, J. W., \& Kahn, J. V. (2006). Research in Education (10 ed.). New York: Pearson.

Bond, M. (2020). Facilitating student engagement through the flipped learning approach in K12: A systematic review. Computers \& Education, 151, 103819. doi:10.1016/j.compedu.2020.103819

Borup, J., Graham, C. R., West, R. E., Archambault, L., \& Spring, K. J. (2020). Academic Communities of Engagement: an expansive lens for examining support structures in blended and online learning. Educational Technology Research and Development. doi:10.1007/s11423-020-09744-X

Bringula, R. (2012). School Choice of Computing Students: A Comparative Perspective from Two Universities. Creative Education, 3, 1070-1078. doi:10.4236/ce.2012.326161

Coffman, T., \& Klinger, M. B. (2016). Authentic Learning Experiences to Build Community in the Blended Classroom. Paper presented at the E-Learn: World Conference on ELearning in Corporate, Government, Healthcare, and Higher Education 2016, Washington, DC, United States. https://www.learntechlib.org/p/173932

Cohen, L., Manion, L., \& Morrison, K. (2007). Research Methods in Education (6th ed.). London: Routledge Falmer.

Conard, M. A., \& Marsh, R. F. (2014). Interest level improves learning but does not moderate the effects of interruptions: An experiment using simultaneous multitasking. Learning and Individual Differences, 30, 112-117. doi:10.1016/j.lindif.2013.11.004

Conrad, C., \& Dunek, L. (2020). Cultivating inquiry-driven learners: The purpose of college education for the twenty-first century (2nd ed.). Baltimore: Johns Hopkins University Press.

Creswell, J. W. (2012). Educational research: Planning, conducting, and evaluating quantitative (4 ed.): Prentice Hall Upper Saddle River, NJ.

Crittenden, W. F., Biel, I. K., \& Lovely III, W. A. (2019). Embracing Digitalization: Student Learning and New Technologies. Journal of Marketing Education, 41(1), 5-14. doi:10.1177/0273475318820895

Davis, F. D. (1989). Perceived usefulness, perceived ease of use, and user acceptance of information technology. MIS quarterly, 319-340. doi:10.2307/249008 
Eskandari, M., \& Soleimani, H. (2016). The effect of collaborative discovery learning using MOODLE on the learning of conditional sentences by Iranian EFL learners. Theory and Practice in Language Studies, 6(1), 153-163. doi:10.17507/tpls.0601.20

Gan, B., Menkhoff, T., \& Smith, R. (2015). Enhancing students' learning process through interactive digital media: New opportunities for collaborative learning. Computers in Human Behavior, 51, 652-663. doi:10.1016/j.chb.2014.12.048

Heggart, K. R., \& Yoo, J. (2018). Getting the Most from Google Classroom: A Pedagogical Framework for Tertiary Educators. Australian Journal of Teacher Education, 43(3), 140-153. doi:10.14221/ajte.2018v43n3.9

Hew, K. F., \& Cheung, W. S. (2008). Attracting student participation in asynchronous online discussions: A case study of peer facilitation. Computers \& Education, 51(3), 11111124. doi:10.1016/j.compedu.2007.11.002

Ifinedo, E., Rikala, J., \& Hämäläinen, T. (2020). Factors affecting Nigerian teacher educators' technology integration: Considering characteristics, knowledge constructs, ICT practices and beliefs. Computers \& Education, 146, 103760. doi:10.1016/j.compedu.2019.103760

Iftakhar, S. (2016). Google classroom: What works and how? Journal of Education and Social Science, 3(2), 12-18.

Judd, T. (2015). Task selection, task switching and multitasking during computer-based independent study. Australasian Journal of Educational Technology, 31(2), 193-207. doi:10.14742/ajet.1992

Khabbaz, M., \& Najjar, R. (2015). Moodle-based distance language learning strategies: An evaluation of technology in language classroom. International Journal of Applied Linguistics and English Literature, 4(4), 205-210. doi:10.7575/aiac.ijalel.v.4n.4p.205

Kumar, J. A., \& Bervell, B. (2019). Google Classroom for mobile learning in higher education: Modelling the initial perceptions of students. Education and Information Technologies, 24(2), 1793-1817.

Lin, Q., Yin, Y., Tang, X., Hadad, R., \& Zhai, X. (2020). Assessing learning in technology-rich maker activities: A systematic review of empirical research. Computers \& Education, 157, 103944. doi:10.1016/j.compedu.2020.103944

Lucas, M. (2020). External barriers affecting the successful implementation of mobile educational interventions. Computers in Human Behavior, 107, 105509. doi:10.1016/j.chb.2018.05.001

Martono, \& Salam, U. (2017). Students' learning in asynchronous discussion forums: A metaanalysis. International Journal of Information and Communication Technology Education (IJICTE), 13(1), 48-60. doi:10.4018/IJICTE.2017010105

Mercer, S., \& Dörnyei, Z. (2020). Engaging Language Learners in Contemporary Classrooms. Cambridge: Cambridge University Press.

Mudrikah, S., Farliana, N., Widhiastuti, R., \& Kardiyem, K. (2019). Utilization of Information Technology and lecturer's role in Accounting learning on the conservation character values and academic performance of "Generation Z" students. Dinamika Pendidikan, 14(2), 178-192. doi:10.15294/dp.v14i2.21890

O'Rourke, B., \& Stickler, U. (2017). Synchronous communication technologies for language learning: Promise and challenges in research and pedagogy. Language Learning in Higher Education, 7, 1-20. doi:10.1515/cercles-2017-0009

Osborne, D. M., Byrne, J. H., Massey, D. L., \& Johnston, A. N. B. (2018). Use of online asynchronous discussion boards to engage students, enhance critical thinking, and 
foster staff-student/student-student collaboration: A mixed method study. Nurse Education Today, 70, 40-46. doi:10.1016/j.nedt.2018.08.014

Purnawarman, P., Susilawati, S., \& Sundayana, W. (2016). The use of Edmodo in teaching writing in a blended learning setting. Indonesian Journal of Applied Linguistics, 5(2), 242-252. doi:10.17509/ijal.v5i2.1348

Rushby, N., \& Surry, D. W. (2016). Mapping the field and terminology The Wiley Handbook of Learning Technology (Vol. 1, pp. 1-14): Wiley Online Library.

Salam, U. (2009). Students' participation in virtual learning environments. Unpublished Ph.D thesis. Melbourne: Monash University.

Satar, H. M., \& Akcan, S. (2018). Pre-service EFL teachers' online participation, interaction, and social presence. Language Learning \& Technology, 22(1), 157-183. doi:10125/44586

Shaharanee, I. N. M., Jamil, J. M., \& Rodzi, S. S. M. (2016a). The application of Google Classroom as a tool for teaching and learning. Journal of Telecommunication, Electronic and Computer Engineering, 8(10), 5-8.

Shaharanee, I. N. M., Jamil, J. M., \& Rodzi, S. S. M. (2016b). Google classroom as a tool for active learning. In F. A. A. Nifa, M. N. M. Nawi, \& A. Hussain (Eds.), Proceedings of the International Conference on Applied Science and Technology 2016 (ICAST'16) (Vol. 1761, pp. 020069-020066). Kedah, Malaysia: AIP Publishing.

Sulissusiawan, A., \& Salam, U. (2017). Students' Use of Online Resources to Enhance Learning Endeavors. International Journal of Virtual and Personal Learning Environments (IJVPLE), 7(2), 44-53. doi:10.4018/IJVPLE.2017070104

Tao, Z., Zhang, B., \& Lai, I. K. W. (2018). Perceived Online Learning Environment and Students' Learning Performance in Higher Education: Mediating Role of Student Engagement. In S. K. S. Cheung, J. Lam, K. C. Li, O. Au, W. W. K. Ma, \& W. S. Ho (Eds.), Technology in Education. Innovative Solutions and Practices (pp. 56-64). Singapore: Springer Singapore.

Turkle, S. (2005). The Second Self: Computers and the human spirit, twentieth anniversary edition. Cambridge: The MIT Press

Turkle, S. (2011). Alone together: Why we expect more from technology and less from each other. New York: Basic Books.

Yulian, R., \& Salam, U. (2014). Students 'perspectives on the application of information and communication technology in english language learning. Jurnal Pendidikan dan Pembelajaran, 3(10). Retrieved from jurnal.untan.ac.id/index.php/ jpdpb/article/view/6595 